\title{
Effect of nitrogen on mechanical properties of CoCrFeMnNi high entropy alloy at room and cryogenic temperatures
}

\author{
M. Klimova , D. Shaysultanov , A. Semenyuk , S. Zherebtsov , G. Salishchev , N. Stepanov * \\ Belgorod State University, Belgorod, 308015, Russia
}

\section{A R T I C L E I N F O}

\section{Article history:}

Received 20 February 2020

Received in revised form

20 July 2020

Accepted 4 August 2020

Available online 7 August 2020

\section{Keywords:}

High entropy alloys

Nitrogen

Solid solution strengthening

Mechanical properties

Deformation mechanisms

\begin{abstract}
A B S T R A C T
Specimens of a CoCrFeMnNi high entropy alloy with different content of nitrogen (0.5-2.0 at.\%) were prepared by induction melting. Microstructure and tensile mechanical behavior of the alloys in the ascast condition were analyzed. The alloys with a low amount of $\mathrm{N}(0.5-1.0$ at.\%) had a single fcc phase coarse-grained microstructure. An increase in the content of $\mathrm{N}$ to 2.0 at.\% resulted in the precipitation of a small amount $(\sim 1 \%)$ of $\mathrm{Cr}$-rich $\mathrm{M}_{2} \mathrm{~N}$ nitride particles. The yield strength of the alloys increased in proportion to the percentage of nitrogen by $117 \mathrm{MPa} / \mathrm{at} \% \mathrm{~N}$ at $293 \mathrm{~K}$ or by $316 \mathrm{MPa} / \mathrm{at} \% \mathrm{~N}$ at $77 \mathrm{~K}$. The observed increase in strength was attributed to solid solution hardening. Ductility of the alloy with 0.5 or 1.0 at.\% of $\mathrm{N}$ increased with a decrease in the testing temperature while ductility of the alloy with 2 at.\% dropped from $67 \%$ at $293 \mathrm{~K}$ to $8 \%$ at $77 \mathrm{~K}$. The plastic deformation of the alloys at both $77 \mathrm{~K}$ or $293 \mathrm{~K}$ was mostly associated with planar dislocation slip. No signs of mechanical twinning were found even at $77 \mathrm{~K}$. Thermo-Calc software was used to produce a quasi-binary CoCrFeMnNi-N phase diagram for comparing the experimental and calculated results. The effect of $\mathrm{N}$ on strengthening and deformation mechanisms at different temperatures was discussed.
\end{abstract}

() 2020 Elsevier B.V. All rights reserved.

\section{Introduction}

The so-called high entropy alloys (HEAs) attract increased attention from the materials scientists worldwide due to their unusual structures and properties [1-5]. The initial idea strongly emphasized the formation of simple substitutional solid solutions by maximization of mixing entropy [1]. Although later it was revealed that the mixing entropy has a limited influence on the phase selection in these alloys [3,6-8], some multi-component equiatomic alloys with a surprisingly stable single substitutional solid solution structure were discovered [3]. The most famous example is the so-called Cantor (CoCrFeMnNi) alloy with a stable face-centered cubic (fcc) structure [7,9-13]. Moreover, some of such HEAs have demonstrated very attractive properties. For example, the Cantor alloy and its derivatives have outstanding fracture toughness at a cryogenic temperature [14-17], while some alloys composed of refractory elements demonstrate superior hightemperature strength [18-20].

\footnotetext{
* Corresponding author. Laboratory of Bulk Nanostructured Materials, Belgorod State University, Pobeda 85, Belgorod, 803015, Russia.

E-mail addresses: stepanov@bsu.edu.ru, stepanov.nikita@icloud.com (N. Stepanov).
}

Although initially the development of HEAs was mostly associated with the usage of elements that are likely to form a substitutional solid solution, interstitial HEAs have recently started to attract considerable attention [21-23]. It is well established that the addition of even small amounts of interstitials can strongly affect the phase stability, mechanical behavior, and properties of alloys. In particular, the effect of carbon on different aspects of late transition metals fcc HEAs including the Cantor alloy was extensively studied. It was revealed that the addition of carbon can significantly improve the strength of some Cantor type alloys both at room and cryogenic temperatures due to solid solution and/or precipitation strengthening [21,23-30]. Carbon also affects the contribution of various deformation mechanisms (mechanical twinning, dislocation slip), yet the exact effect remains quite debatable [23,24,27,29,31-34].

Meanwhile, information on the effect of other interstitial elements on the structure and properties of HEAs is quite limited. For instance, nitrogen is known to be an efficient strengthener of austenitic (fcc) steels [35]; nitrogen doping is widely used in cryogenic steels [36,37]. However systematic analysis of nitrogen influence on the structure and mechanical behavior of bulk fcc HEAs has not been performed so far [38-41]. Therefore, in present work we have examined structures and tensile properties at room 
and cryogenic temperatures of the equiatomic $\mathrm{CoCrFeMnNi}$ alloy doped with different amounts of $\mathrm{N}$. The microstructures of the alloy after tensile tests were also investigated.

\section{Materials and methods}

The equiatomic CoCrFeMnNi alloy with different amounts of nitrogen (the nominal concentrations were $0.5,1.0$, or 2.0 at.\%) was used in the current study. The ingots were produced using mixtures of pure ( $\geq 99.9 \%$ wt.\%) constitutive elements by vacuum induction melting. Nitrogen was added in the form of ferrochrome nitride. The produced ingots of $\sim 400 \mathrm{~g}$ had a rectangular shape measured $65 \times 40 \times 17 \mathrm{~mm}^{3}$. The results of chemical analysis (Table 1) indicated that the measured composition was close to the nominal one. The concentrations of the principal elements, listed in Table 1, were determined by energy dispersive spectrometry (EDS) analysis; the concentration of nitrogen was determined by thermalcombustion analysis (Leco ONH 836 analyzer; the accuracy of the measurements is within $3 \%$ ). Note that the difference between the nominal and actual concentrations of $\mathrm{N}$ was $\sim 10 \%$, therefore the nominal percentage of $\mathrm{N}$ will be used further.

Specimens for microstructure analysis and mechanical testing were cut from the as-cast ingots using an electric discharge machine. Scanning (SEM) and transmission (TEM) electron microscopy were used for structural analysis. The samples for SEM observations were prepared by careful mechanical polishing. SEM back-scattered electron (BSE) images were taken using a FEI Quanta 3D microscope equipped with an EDS detector. TEM investigations were performed using a JEOL JEM-2100 microscope operated at $200 \mathrm{kV}$ and equipped with an EDS detector. Samples for TEM analysis were prepared by the conventional twin-jet electro-polishing of mechanically pre-thinned to $100 \mathrm{~mm}$ foils, in a mixture of $90 \%$ $\mathrm{CH} 3 \mathrm{COOH}$ and $10 \% \mathrm{HClO} 4$ at $30 \mathrm{~V}$ potential at room temperature.

Tensile testing was used to evaluate the mechanical properties of the alloys. The tensile tests at room (293 K) temperature (RT), or cryogenic $(77 \mathrm{~K})$ temperature of dog-bone flat specimens (gauge measured $6 \times 3 \times 1 \mathrm{~mm}^{3}$ ) were conducted using an Instron 5882 universal testing machine at a constant crosshead velocity corresponded to a nominal strain rate of $10^{-3} \mathrm{~s}^{-1}$. For cryogenic testing, the test specimen and both grips were immersed in an open-top vessel filled with liquid nitrogen whose level was continuously monitored and adjusted to ensure adequate temperature control. The specimen held for a couple of minutes before the test onset to equilibrate the temperature. Elongation to fracture was determined by measuring the spaces between marks designating the gauge length before and after the test. At least 3 specimens for each composition and temperature were tested. Extra specimens were tensioned to $20 \%$ strain; these specimens were used further for TEM examination of the deformed microstructure. In the case of the alloy with 2 at.\% of $\mathrm{N}$ tested at $77 \mathrm{~K}$, the experiment was stopped at $5 \%$ strain due to limited ductility.

Thermo-Calc software (version 2020a) with a database for steels (TCFE7) was used to produce a quasi-binary phase CoCrFeMnNi-N phase diagram and evaluate the effect of $\mathrm{N}$ on SFE. The TCFE7

Table 1

Chemical composition of the program alloys depending on the nominal nitrogen concentration, in at.\%.

\begin{tabular}{llllllll}
\hline \multirow{2}{*}{ Nominal nitrogen content, at.\% } & \multicolumn{6}{c}{ The concentration of the elements, at.\% } \\
\cline { 2 - 8 } & $\mathrm{Co}$ & $\mathrm{Cr}$ & $\mathrm{Fe}$ & $\mathrm{Mn}$ & $\mathrm{Ni}$ & $\mathrm{N}$ \\
\hline 0.5 & 20.10 & 20.10 & 19.61 & 19.80 & 19.96 & 0.45 \\
1.0 & 19.81 & 20.05 & 19.71 & 19.55 & 20.01 & 0.88 \\
2.0 & 19.52 & 19.71 & 19.45 & 19.48 & 19.61 & 2.21 \\
\hline
\end{tabular}

database was used instead of a specialized database for high entropy alloys (TCHEA3) because it is better suited for the description of $\mathrm{N}$-doped alloys.

\section{Results}

\subsection{Microstructure of the CoCrFeMnNiN $\mathrm{N}_{x}$ alloys in the as-cast condition}

The XRD patterns of the CoCrFeMnNiN ${ }_{\mathrm{X}}$ alloys with different contents of $\mathrm{N}$ are shown in Fig. 1a. All the observed peaks can be ascribed to the fcc lattice; no other phases were found. The lattice parameter of the fcc phase gradually increased from $0.359 \mathrm{~nm}$ in the alloy with 0.5 at.\% of $\mathrm{N}$ to $0.362 \mathrm{~nm}$ in the alloy with 2.0 at.\% of $\mathrm{N}$ (Fig. 3b). A linear relationship between the $\mathrm{N}$ concentration and the fcc lattice parameter worth noting; the slope of the line was $\approx 0.002 \mathrm{~nm} / \mathrm{at} \% \mathrm{~N}$.

The microstructure of the examined alloys is shown in Fig. 2. SEM-BSE images of the alloys with 0.5 or 1.0 at.\% of N (Fig. 2a or c) demonstrate in both cases a coarse-grained single-phase microstructure in accordance with the XRD data (Fig. 1a). The average grain size was $175 \pm 90 \mu \mathrm{m}$ and $165 \pm 75 \mu \mathrm{m}$ in the alloys with 0.5 or 1.0 at.\% of $\mathrm{N}$, respectively. The grains often had curved irregular boundaries, most probably due to a non-equilibrium character of the as-cast microstructure. Note that curved irregular grain boundaries can be found in the as-cast CoCrFeMnNi alloy [42], and, according to many sources, alloying with interstitial carbon does not affect the as-cast grains morphology of similar alloys [22,24,29,34]. However, no signs of dendritic segregations were found. TEM examinations (Fig. 2b and d) did also not reveal any signs of secondary phases. Some dislocations, arranged in planar configurations, were found, most probably due to internal stresses in the as-cast alloys.

A low-magnification SEM image of the alloy with 2 at.\% of $\mathrm{N}$ (Fig. 2e) is very similar to those of the alloys with lower $\mathrm{N}$ contents (Fig. 2a or c). Somewhat lower grain size $(135 \pm 65 \mu \mathrm{m})$ must be mentioned. Also, some elongated secondary phase particles located at grain boundaries were found by TEM (Fig. 2f). These precipitates were not revealed by XRD most likely because of their low fraction ( 1\%). TEM selected area electron diffraction pattern analysis has revealed that these particles were hexagonal $\mathrm{M}_{2} \mathrm{~N}$ phase. They had an elongated shape with the average transversal and longitudinal dimensions of $\sim 50 \mathrm{~nm}$ and $\sim 300 \mathrm{~nm}$, respectively. EDS measurements have shown that the $\mathrm{M}_{2} \mathrm{~N}$ particles were mostly composed of $\mathrm{Cr}$. Presumably, precipitation of the $\mathrm{M}_{2} \mathrm{~N}$ particles can be responsible for the lower fcc grain size in the alloy with 2 at.\% of N.

\subsection{Mechanical properties}

The tensile stress-strain curves of the $\mathrm{CoCrFeMnNiN}_{\mathrm{x}}$ alloys with different $\mathrm{N}$ contents obtained at $293 \mathrm{~K}$ and $77 \mathrm{~K}$ are shown in Fig. 3. For comparison, data for a similar undoped $\mathrm{CoCr}_{0.25} \mathrm{FeMnNi}$ alloy [34] was added. Note that the reduction of the $\mathrm{Cr}$ content is not expected to have pronounced effect on the mechanical properties of the alloys. For example, the yield strength of the equiatomic CoCrFeMnNi [14]] and Cr-free CoFeMnNi [43] alloys with similar recrystallized microstructures (grain size of $50 \mu \mathrm{m}$ and $48 \mu \mathrm{m}$, respectively) at room temperature was $\sim 200 \mathrm{MPa}$ and $\sim 180 \mathrm{MPa}$, respectively. The resulting mechanical properties of the program alloys, namely the yield strength, ultimate tensile strength, uniform elongation, and elongation to fracture are summarized in Table 2. At room temperature behavior of all alloys was quite similar: they exhibited relatively low yield stress and a prolonged strain hardening stage which results in very high ductility (Fig. 3a). The alloys demonstrated an increase in both strength and ductility with an 

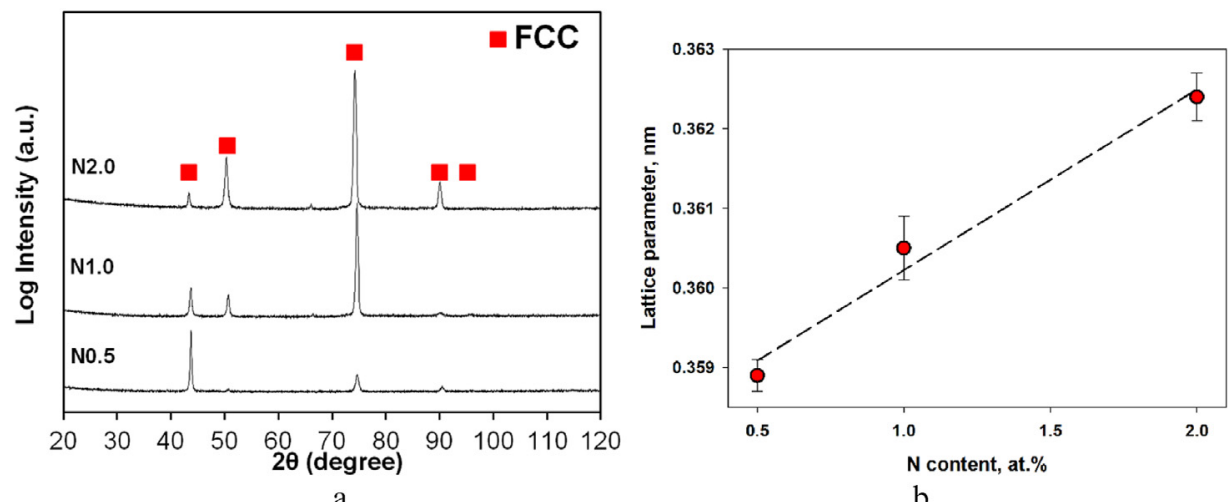

Fig. 1. XRD analysis of the $\mathrm{CoCrFeMnNiN}$ alloys with different $\mathrm{N}$ contents: (a) - XRD patterns; (b) - dependence of the lattice parameter on the content of nitrogen.

increase in the nitrogen content. For example, the yield strength increased from $220 \mathrm{MPa}$ to $395 \mathrm{MPa}$ with an increase in the N percentage from 0.5 to 2.0 at.\%, while corresponding values of elongation to fracture were 65 and 67\%, respectively.

A decrease in the testing temperature to $77 \mathrm{~K}$ had somewhat unexpected result (Fig. 3b). The alloys became much stronger in comparison with the room temperature case; the yield strength of the alloy with 0.5 at.\% of $\mathrm{N}$ was $495 \mathrm{MPa}$, while the alloy with 2.0 at.\% of $\mathrm{N}$ had strength of $960 \mathrm{MPa}$. The alloys' behavior after the yielding point depended strongly on the $\mathrm{N}$ percentage. At $77 \mathrm{~K}$ the alloy without nitrogen and alloys doped with 0.5 or 1.0 at.\% of $\mathrm{N}$ demonstrated an extended strain hardening stage and attained somewhat better ductility than that at room temperature. For example, elongation to fracture increased to 90 and $72 \%$ for the alloys with 0.5 and 1.0 at.\%, respectively. Meanwhile the alloy with 2 at.\% of $\mathrm{N}$ demonstrated a very short strain hardening stage and fractured shortly after the yielding point; the corresponding elongation to fracture was only $8 \%$.

Dependences of the yield strength of the CoCrFeMnNiN $\mathrm{x}_{\mathrm{x}}$ alloys on nitrogen content at $293 \mathrm{~K}$ or $77 \mathrm{~K}$ are shown in Fig. 4. A linear relationship was found in both cases. Yet, the slope of the line increased with a decrease in temperature from $117 \mathrm{MPa} / \mathrm{at} \% \mathrm{~N}$ at $293 \mathrm{~K}$ to $316 \mathrm{MPa} /$ at\% $\mathrm{N}$ at $77 \mathrm{~K}$. The approximations of the lines shown in Fig. 4 is consistent with the yield strength of the undoped $\mathrm{CoCr}_{0.25} \mathrm{FeMnNi}$ alloy [34] (i.e. the $\mathrm{N}$ content equal to $0 \%$ ).

Fig. 5 shows strain hardening curves of the CoCrFeNiMnN $\mathrm{N}_{\mathrm{x}}$ alloys with different nitrogen contents (undoped $\mathrm{CoCr}_{0.25} \mathrm{FeMnNi}$ [34], 0.5, 1.0, and 2.0 at.\%) obtained during tension at room or cryogenic temperatures. At $293 \mathrm{~K}$ the alloys showed qualitatively similar behavior irrespective of the nitrogen content (Fig. 5a). The strain hardening rate was $\sim 900-1200 \mathrm{MPa}$ at the initial stages of deformation. A noticeable increase in the strain hardening rate occurred during further deformation till a true strain of $\sim 0.40-0.55$, followed by a gradual decrease. In the alloys with a higher content of nitrogen the strain hardening rate increased more pronouncedly during larger strain. For example, the alloy with 0.5 at.\% of $\mathrm{N}$ reached the maximum value of $d \sigma / d \varepsilon \approx 1400-1500 \mathrm{MPa}$ at $\varepsilon \approx 0.4$, while the alloy with 2 at.\% of $\mathrm{N}$ reached $d \sigma / d \varepsilon \approx 2000 \mathrm{MPa}$ at $\varepsilon \approx 0.5$.

At a lower temperature of $77 \mathrm{~K}$ strain hardening significantly depended on the nitrogen content (Fig. 5b). The alloys with 0.5 or 1.0 at.\% of $\mathrm{N}$ showed similar behavior to that observed at room temperature, yet the strain hardening capacity was found to be better. The values of $d \sigma / d \varepsilon$ at the initial stage of deformation were found to be $1100-1400 \mathrm{MPa}$. Progressive straining resulted in a pronounced increase in $d \sigma / d \varepsilon$ to $\approx 2300 \mathrm{MPa}$ in the alloy with 0.5 at.\% of $\mathrm{N}$ and to $\approx 2700 \mathrm{MPa}$ in the alloy with 1.0 at.\% of $\mathrm{N}$ at strains of 0.4-0.6. After the evident steady-state stage, the $\mathrm{d} \sigma /$ $\mathrm{d} \varepsilon$ ratio decreased quickly. Meanwhile in the alloy with 2 at.\% of $\mathrm{N}$ $\mathrm{d} \sigma / \mathrm{d} \varepsilon$ was $\approx 1500 \mathrm{MPa}$ at the initial stages of deformation $(\varepsilon \approx 0.05)$ and then the strain hardening abruptly diminished with further deformation.

Noticeable serrations were observed at both temperatures on all the strain hardening curves; no systematic effect of either the chemical composition or testing temperature on the serration behavior was revealed, however

The fracture surfaces of the alloys depended considerably on the content of nitrogen and testing temperature. At $293 \mathrm{~K}$ all alloys showed after tension tests dimple fracture, typical of ductile metallic materials (examples for the alloys with 1.0 at.\% or 2.0 at.\% of nitrogen are shown in Fig. 6a or b, respectively). The formation of the dimples in the alloy with 2.0 at.\% of $\mathrm{N}$ was not evidently associated with the presence of $\mathrm{Cr}$-rich $\mathrm{M}_{2} \mathrm{~N}$ particles. A decrease in the testing temperature to $77 \mathrm{~K}$ did not result in fracture mechanism changing in the alloy with 0.5 or 1.0 at.\% of $\mathrm{N}$, however, some decrease in the depth of the dimple was observed (Fig. 6c). Meanwhile in the alloy with 2.0 at.\% of $\mathrm{N}$ the fracture surface obtained at cryogenic temperature consisted mainly of flat cleavage facets suggesting a brittle character of fracture (Fig. 6d) which is in agreement with the mechanical behavior of the alloy (Figs. $3 \mathrm{~b}$ and 5b).

\subsection{Deformation microstructures}

Fig. 7 shows TEM images of the $\operatorname{CoCrFeMnNiN}_{\mathrm{x}}(\mathrm{x}=0.5,1.0$, 2.0 at.\%) alloys microstructure after tensile testing at $77 \mathrm{~K}$ and $293 \mathrm{~K}$. Tensile testing of the alloy with the lowest $\mathrm{N}$ percentage (0.5 at.\%) at room temperature resulted in the development of intensive dislocation slip along a preferred direction and in the formation of slip bands (Fig. 7a). Some individual dislocations or dislocation pile-ups, however, were found between the bands, suggesting operation of secondary slip systems. A decrease in the testing temperature to $77 \mathrm{~K}$ led to a noticeable increase in the overall dislocation density in the alloy with 0.5 at.\% of N (Fig. 7b). Dislocations were also mostly arranged in the bands, aligned in two different directions. However, the slip bands were much more diffuse in comparison with those formed at $293 \mathrm{~K}$. Deformation twins were not found at both deformation temperatures.

An increase in the nitrogen concentration to 1.0 at.\% did not result in significant changes in the microstructure after testing at $293 \mathrm{~K}$ (Fig. 7c). The microstructure contained slip bands aligned in mainly one direction and some pile-ups between the bands. The bands were quite diffuse, however. Microstructure of the alloy with 1.0 at.\% of $\mathrm{N}$ after tension at $77 \mathrm{~K}$ (Fig. 7d) was composed of slip 


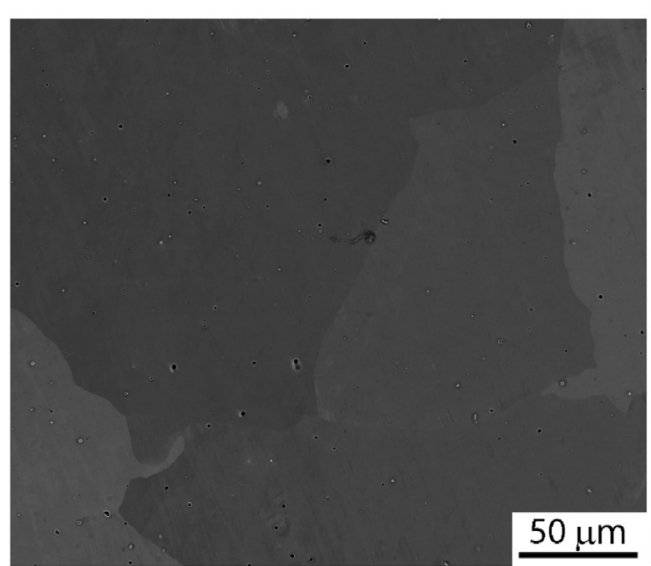

a

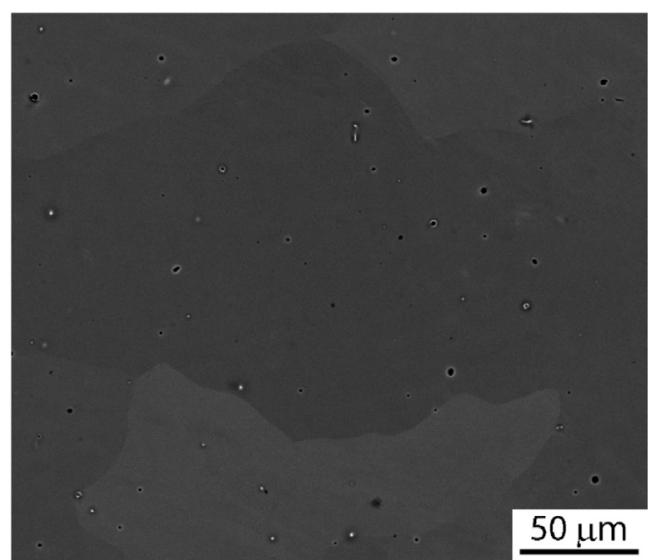

$\mathrm{c}$

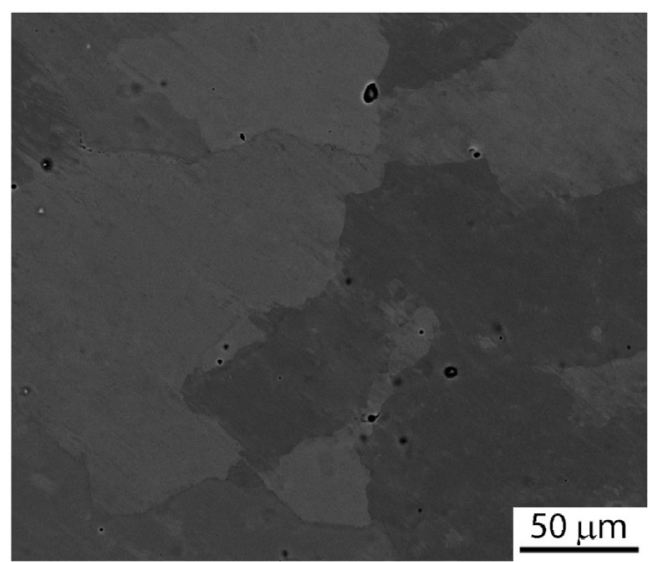

e

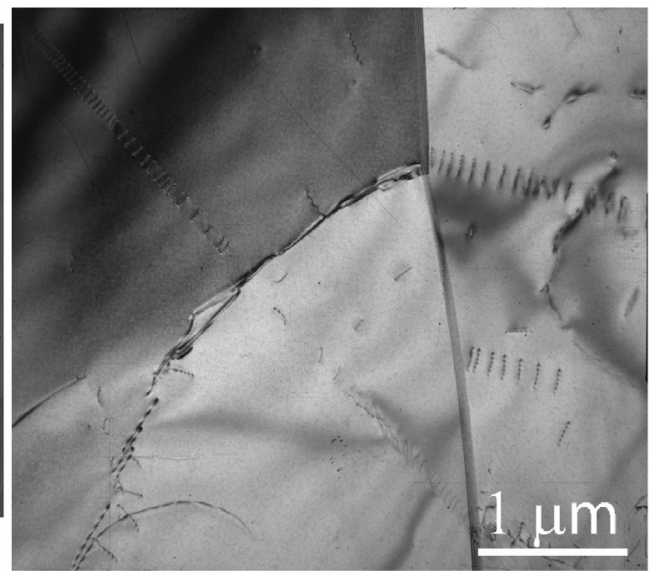

b

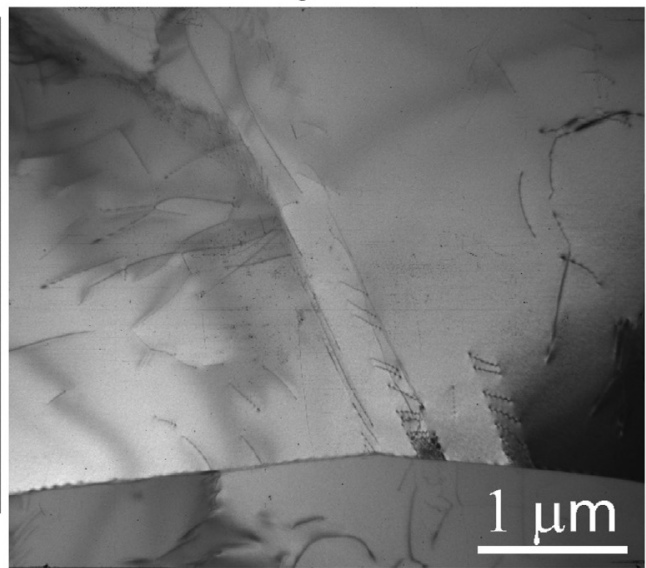

$\mathrm{d}$

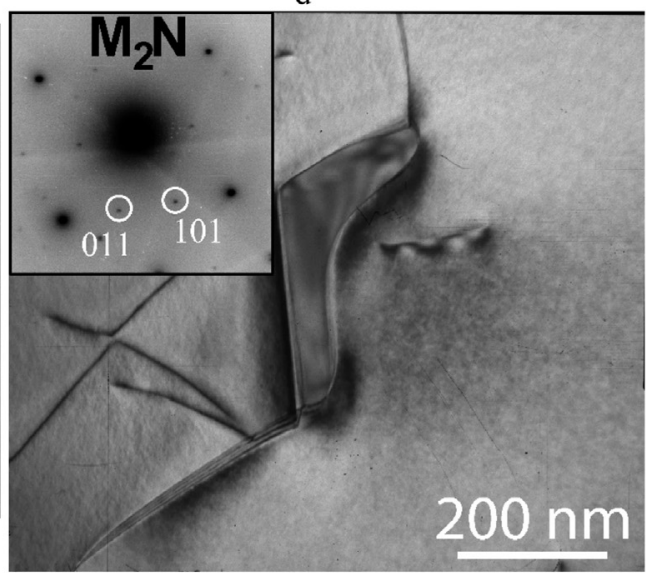

f

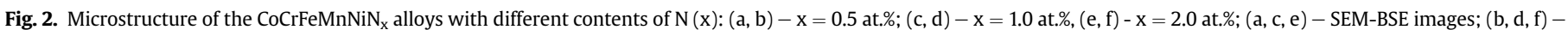
TEM-bright-field images. A selected area electron diffraction pattern taken from a $\mathrm{M}_{2} \mathrm{~N}$ precipitate is shown in Fig. $2 \mathrm{f}$.

bands aligned in two different directions. The typical diffraction pattern for these slip bands is given in insert on Fig. $7 \mathrm{~d}$. It is shown that bands were formed in the $\{111\}$ planes, which are slip planes in fcc alloys. In contrast to the alloy with 0.5 at.\% N (Fig. 7b), these bands had sharp well-defined boundaries; very few dislocations were observed in between the bands. Note also characteristic steps at interceptions of the bands. The absence of twinning patterns on the [02-2] zone axis diffraction (insert on Fig. 7d) confirms that deformation twinning was not revealed in the microstructure.

Finally, the alloy with 2 at.\% of $\mathrm{N}$ after tension at room temperature (Fig. 7e) demonstrated quite a similar microstructure to those of previous alloys. The main structural constituents were slip bands, aligned in mainly one direction. Some individual dislocations were found between the bands. At $77 \mathrm{~K}$, however, a similar structure with low density of dislocation arranged in planar arrays was found (Fig. 7f); most probably due to a much lower attained strain (5\%) in comparison with the rest of the specimens (20\%).

\section{Discussion}

In this study, the effect of nitrogen (0.5-2.0 at.\%) on the structure and mechanical properties of CoCrFeMnNi-based alloy in the 

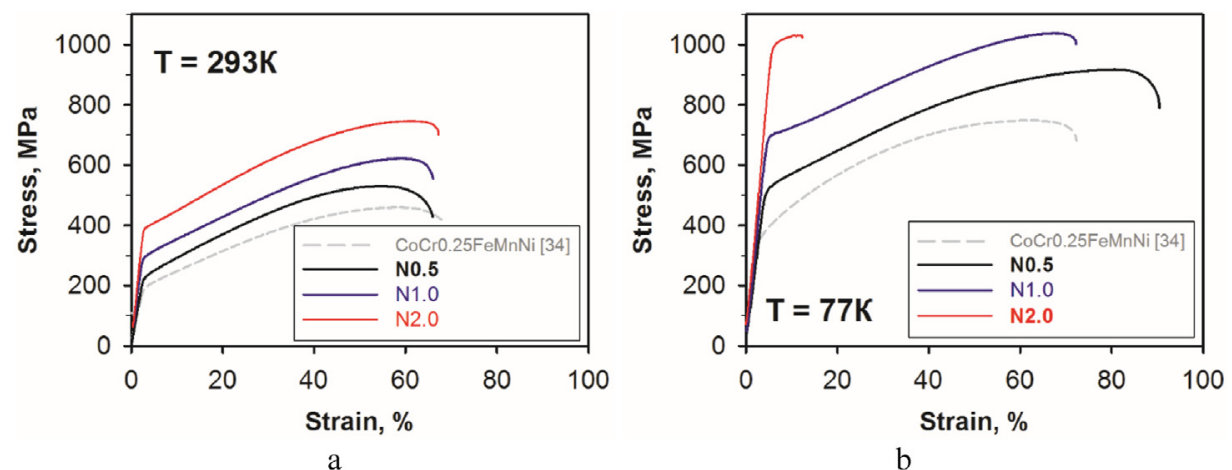

Fig. 3. Tensile stress-strain curves of the CoCrFeMnNiN ${ }_{x}(x=0.0,0.5,1.0,2.0)$ obtained at (a) $-293 \mathrm{~K}$ and (b) $77 \mathrm{~K}$.

Table 2

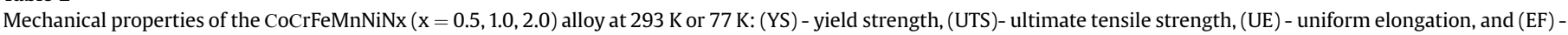
elongation to fracture.

\begin{tabular}{|c|c|c|c|c|c|}
\hline Nitrogen content, at.\% & Testing temperature, $\mathrm{K}$ & YS, MPa & UTS, MPa & UE, \% & $\mathrm{EF}, \%$ \\
\hline \multirow[t]{2}{*}{0.5} & 77 & 495 & 920 & 78 & 90 \\
\hline & 293 & 220 & 530 & 52 & 65 \\
\hline \multirow[t]{2}{*}{1.0} & 77 & 650 & 1038 & 66 & 72 \\
\hline & 293 & 275 & 610 & 54 & 66 \\
\hline \multirow[t]{2}{*}{2.0} & 77 & 960 & 1030 & 4 & 8 \\
\hline & 293 & 395 & 765 & 60 & 67 \\
\hline
\end{tabular}

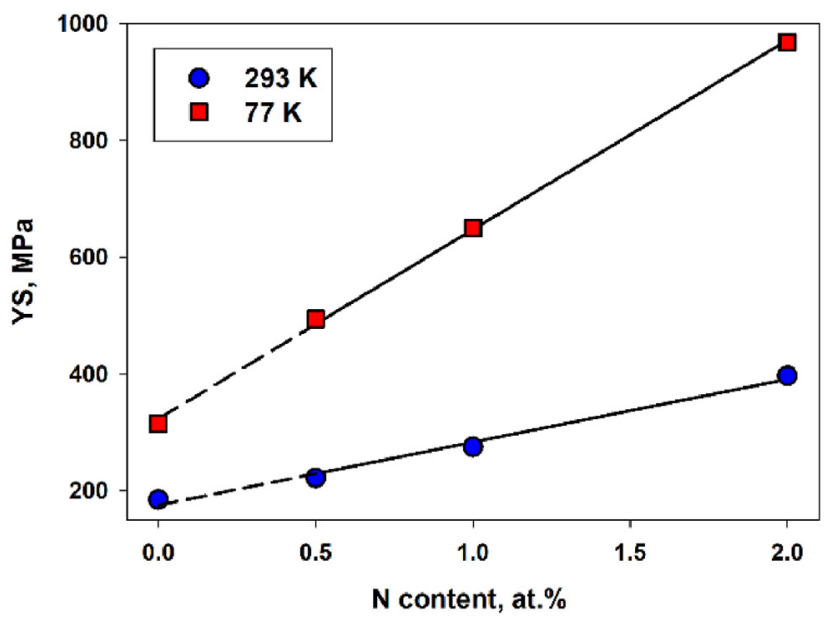

Fig. 4. The dependence of the yield strength (YS) of the CoCrFeMnNiN ${ }_{x}(x=0.0,0.5$, $1.0,2.0$ ) alloy at $293 \mathrm{~K}$ and $77 \mathrm{~K}$ on the $\mathrm{N}$ content.

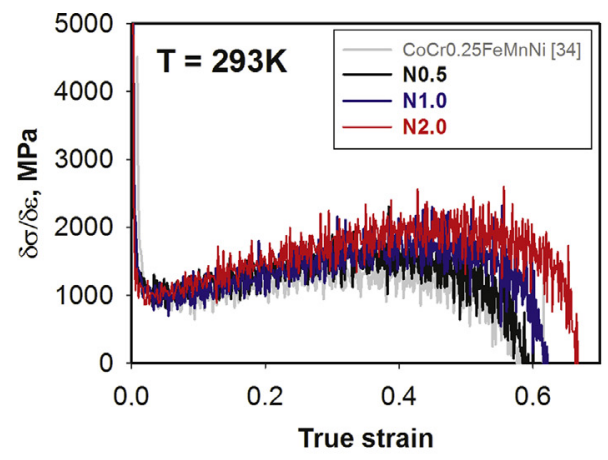

a as-cast condition was examined. Note that although several works on N-doped fcc HEAs are already available [38-41], to the best of the authors knowledge, none of them has examined the effect of the content of nitrogen systematically.

The addition of nitrogen has quite a limited effect on microstructure. The alloys with 0.5 and 1.0 at.\% of $\mathrm{N}$ had the single fcc phase microstructure, typical of the "pure" as-cast CoCrFeMnNi alloy (Fig. 2a-d). Only a limited amount of the $\mathrm{Cr}$-rich $\mathrm{M}_{2} \mathrm{~N}$ particles was found in the alloy with 2 at.\% of $\mathrm{N}$ (Fig. 2e and f). In addition, the linear dependence of the fcc lattice parameter on the $\mathrm{N}$ content suggests that nitrogen was mostly dissolved in the fcc solid solution (Fig. 1b).

Reasonably good solubility of nitrogen in the CoCrFeMnNi alloys contrasts with earlier results obtained for other interstitial elements like carbon. For instance, the extensive formation of carbides in the as-cast CoCrFeMnNi-based alloys doped with $\sim 2$ at.\% of $\mathrm{C}$ was reported several times [22,29]. Better solubility of $\mathrm{N}$ in the fcc solid solution can be attributed to a smaller size of the $\mathrm{N}$ atoms in comparison with C: $0.155 \mathrm{~nm}$ and $0.170 \mathrm{~nm}$, respectively. The size of

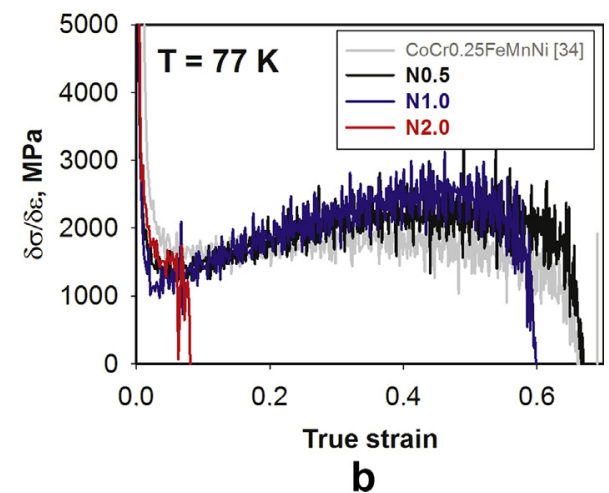

Fig. 5. Strain hardening curves of the CoCrFeMnNiN ${ }_{x}(x=0.0,0.5,1.0,2.0)$ at (a) $293 \mathrm{~K}$ and (b) $77 \mathrm{~K}$. 


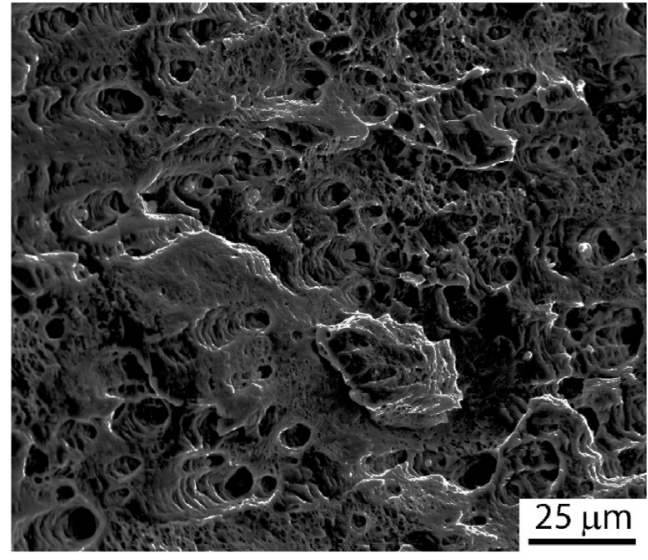

a

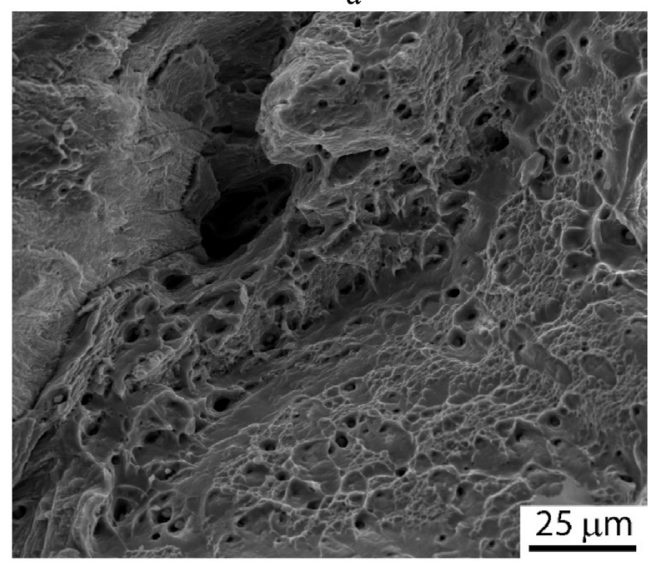

c

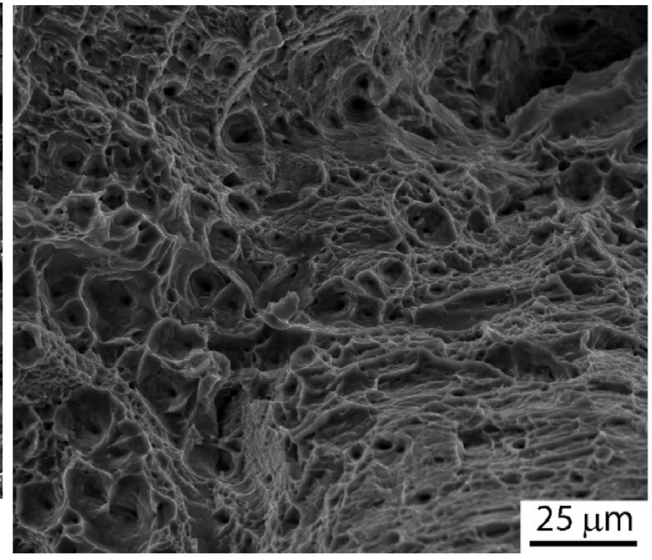

b

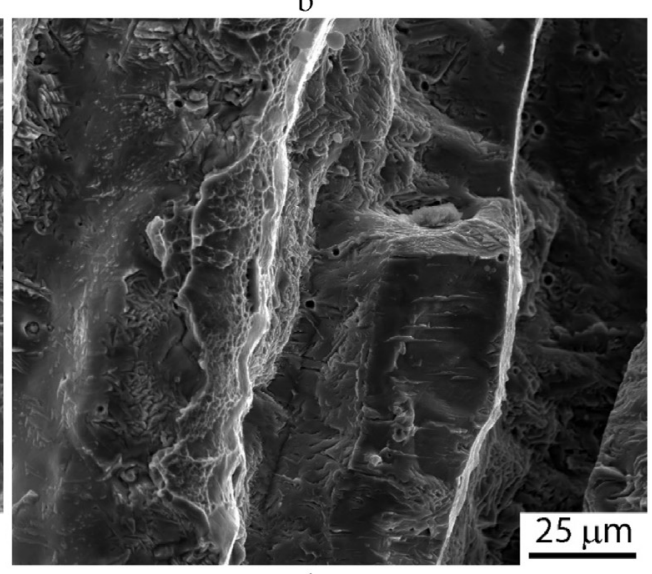

$\mathrm{d}$

Fig. 6. Fracture surfaces of tensile samples of the CoCrFeMnNiN alloys (a, b) $\mathrm{x}=1.0$ at.\%, (c, d) $-\mathrm{x}=2.0$ at.\% after tension at (a, c) - $293 \mathrm{~K}$, (b, d) - $77 \mathrm{~K}$.

the interstitial sites in the fcc lattice is $0.41 a$, where $a$ is the lattice parameter. The $a$ value of the examined alloys can be roughly estimated as $a \approx 0.360 \mathrm{~nm}$ (Fig. 1b), then the estimated interstitial site size is $\approx 0.148 \mathrm{~nm}$. The difference between the interstitial site and the size of the $\mathrm{C}$ and $\mathrm{N}$ atoms is $\approx 15 \%$ and $\approx 5 \%$, respectively.

Another tool to analyze the alloying effect on the structure of the alloys is a phase diagram. The phase diagram for a multicomponent alloy can be produced using the CALPHAD (CALculations of PHAse Diagrams) approach [44]. In this work, we have used a Thermo-Calc software to produce a CoCrFeMnNi-N quasi-binary phase diagram (Fig. 8). The undoped CoCrFeMnNi alloys solidify at $\sim 1300{ }^{\circ} \mathrm{C}$. After solidification, a wide single fcc phase field is observed. Secondary phases (bcc and sigma phases) precipitate at $660^{\circ} \mathrm{C}$ and $570{ }^{\circ} \mathrm{C}$, respectively. The addition of $\mathrm{N}$ results in a pronounced decrease in the solvus temperature of the bcc phase (to $520^{\circ} \mathrm{C}$ at 2 at.\% of $\mathrm{N}$ ) and in some decrease in solvus temperature of the sigma phase (to $\left.540{ }^{\circ} \mathrm{C}\right)$.

However, the most significant effect of the $\mathrm{N}$ doping is associated with the $\mathrm{Cr}$-rich $\mathrm{M}_{2} \mathrm{~N}$ phase formation. The solvus temperature of these nitrides quickly increases with an increase in the $\mathrm{N}$ percentage reaching the maximum at 0.6 at.\% of N. Further increase in the content of $\mathrm{N}$ does not result in noticeable changes in the $\mathrm{M}_{2} \mathrm{~N}$ solvus temperature, which remains $\sim 1250{ }^{\circ} \mathrm{C}$. These results are in agreement with data obtained in Ref. [38], with the exception of some minor inconsistencies that can be attributed to different databases used for calculation (TCFE7 in present study and TCNI8 in Ref. [38]). For example, according to Ref. [38] the $\mathrm{M}_{2} \mathrm{~N}$ nitrides are expected to precipitate from the liquid directly at high nitrogen concentration
( $>1.4$ at.\%) whereas in present study even in the alloys with a high $\mathrm{N}$ percentage a narrow single fcc phase window $\left(\sim 1250-1270{ }^{\circ} \mathrm{C}\right)$ exist. This differs from the case of $\mathrm{C}$-doped CoCrFeMnNi alloys also. The single fcc phase field boundaries in $\mathrm{CoCrFeMnNi-C} \mathrm{quasi-binary}$ are shown with a red dashed line in Fig. 8. Apparently, the solubility of $\mathrm{C}$ in the fcc solid solution (a temperature range within which the single fcc phase exists) at low $\mathrm{C} / \mathrm{N}$ concentrations $(<0.8$ at.\%) is better. However, in the C-doped alloys, starting from 0.9 at.\% C, carbides precipitate directly from the liquid phase while the single fcc phase field disappears. Low amounts of the nitrides found in $\mathrm{N}$ doped alloys in the current work can most probably be associated with the fact that the $\mathrm{M}_{2} \mathrm{~N}$ nitrides (in contrast to carbides) do not precipitate from the liquid phase.

Another effect of nitrogen was associated with the significant increase in strength of the alloys (Figs. 3-4, Table 2). It is already well established that interstitial atoms like carbon can have a strong positive effect on strength, mostly due to (i) solid solution $[21,24,34,45]$ or (ii) precipitation hardening $[23,28,46]$. In addition, grain boundary strengthening can play an important role $[25,28]$. However, the size of the fcc grains was rather similar in all the examined alloys (Fig. 2a, c, d). The estimation of grain boundary strengthening using Hall-Petch coefficient reported in for the CoCrFeMnNi [14] yielded only $\approx 5$ MPa difference between the alloys with 0.5 and 2.0 at.\% of $\mathrm{N}$. The $\mathrm{M}_{2} \mathrm{~N}$ precipitates found in the alloy with 2.0 at.\% of $\mathrm{N}$ have a very limited fraction (Fig. 2f), and are mostly found at the grain boundaries. Therefore, the observed increase in strength (Fig. 4) can be predominantly attributed to solid solution strengthening. 


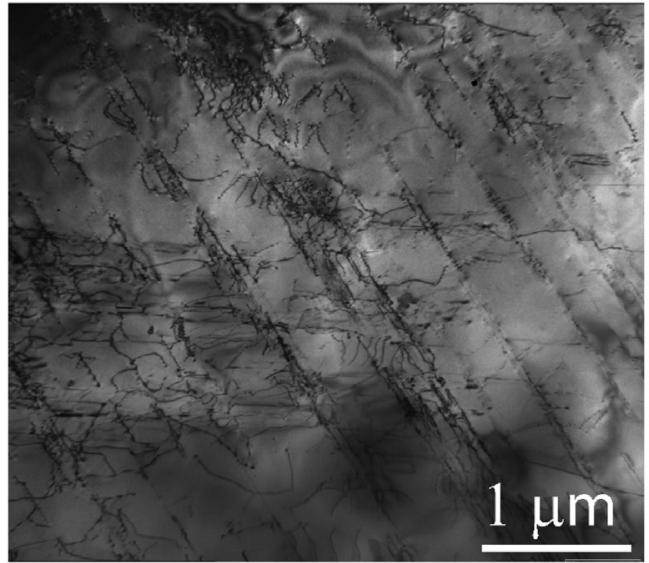

a

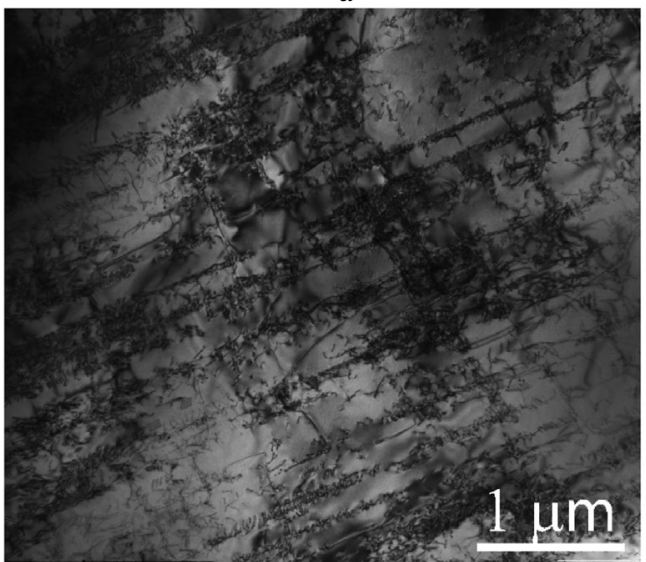

C

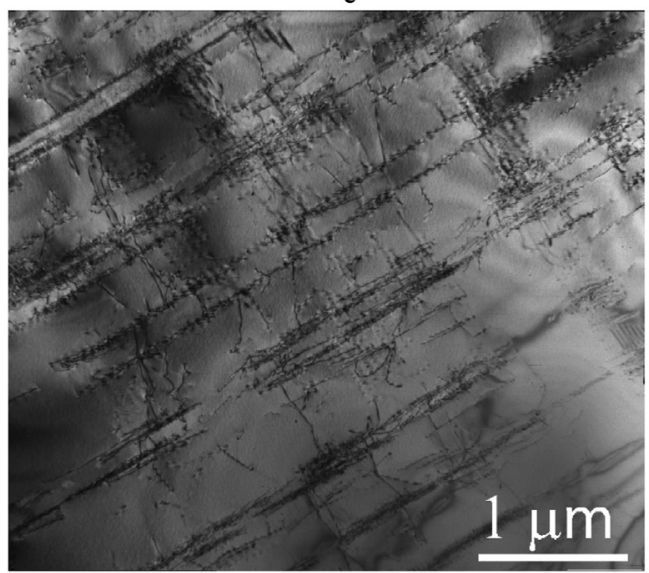

e

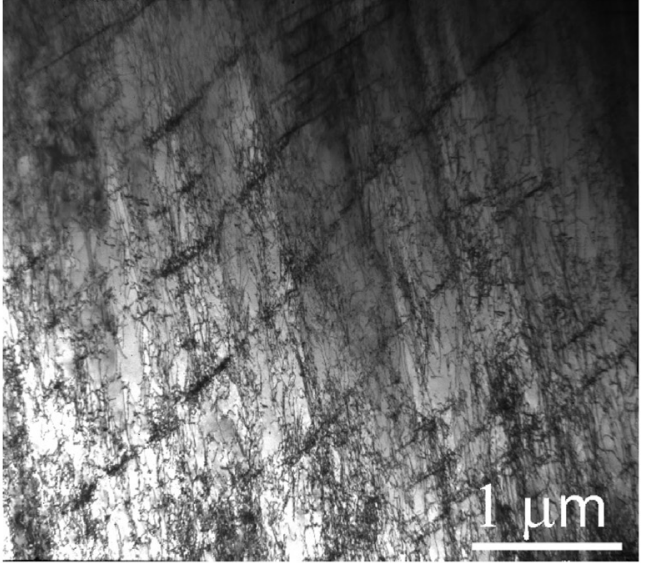

b

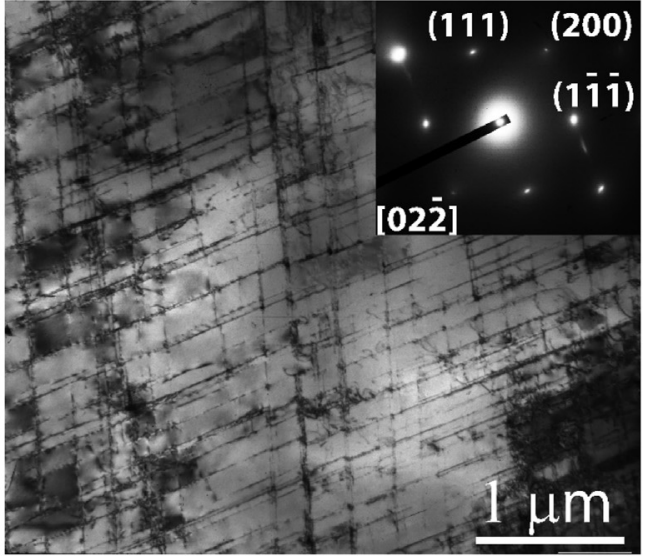

d

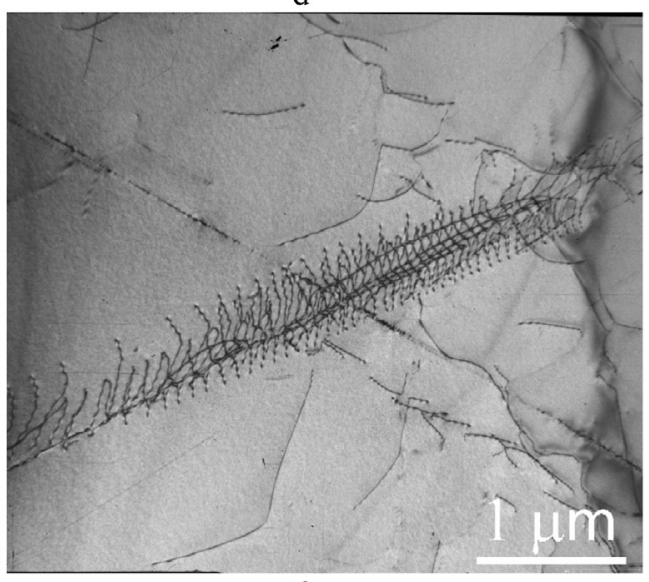

$f$

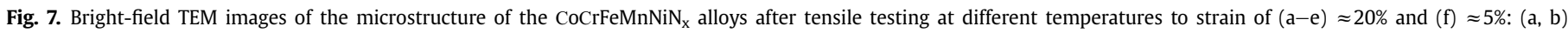
$\mathrm{x}=0.5$ at.\%, (c, d) $-\mathrm{x}=1.0$ at.\%, (e, f) $-\mathrm{x}=2.0$ at.\%; (a, c, e) $-293 \mathrm{~K}$, (b, d, f) $-77 \mathrm{~K}$.

The observed dependence of the yield strength on the content of $\mathrm{N}$ (Fig. 4) is linear $\left(c^{1}\right)$, whereas classic models suggest rather $c^{1 / 2}$ [47] or $c^{2 / 3}$ [48] dependencies. Nevertheless, linear relationships are also quite often observed, for example, in fcc HEAs doped with carbon $[21,34,45]$. It is interesting to compare the strengthening coefficients found in different alloys. It is generally accepted that solid solution strengthening is associated with lattice and modulus distortions, generated by solute atoms. The lattice distortion can be readily estimated from the changes in the lattice parameter. For example, in the investigated CoCrFeMnNiNx alloys the lattice distortion per atomic percentage of $\mathrm{N}(\Delta \mathrm{a} / \Delta \mathrm{c})$ is $0.002 \mathrm{~nm} / \mathrm{at} \% \mathrm{~N}$. In
Fig. 9 the strengthening coefficients $(\Delta Y S / \Delta c)$ at $293 \mathrm{~K}$ and lattice distortions, $\Delta a / \Delta c$, obtained here for the CoCrFeMnNi-N, $\mathrm{Fe}_{40.4} \mathrm{Ni}_{11.3} \mathrm{Mn}_{34.8} \mathrm{Al}_{7.5} \mathrm{Cr}_{6}-\mathrm{C}$ [24], $\mathrm{Fe}_{40} \mathrm{Mn}_{40} \mathrm{Co}_{10} \mathrm{Cr}_{10}-\mathrm{C}$ [45] (compositions are given in at.\%), and $\mathrm{CoCr}_{0.25} \mathrm{FeMnNi}-\mathrm{C}$ [34] (subscripts indicate molar fractions, no subscript is equal to 1) alloys was plotted.

Fig. 9 clearly shows that there is a linear relationship between the $\Delta Y S / \Delta c$ and $\Delta a / \Delta c$ values found in the interstitial HEAs systems. This finding implies that the solid solution strengthening in chemically different alloying systems obeys the same regularities. Moreover, the solid solution strengthening can be maximized by 


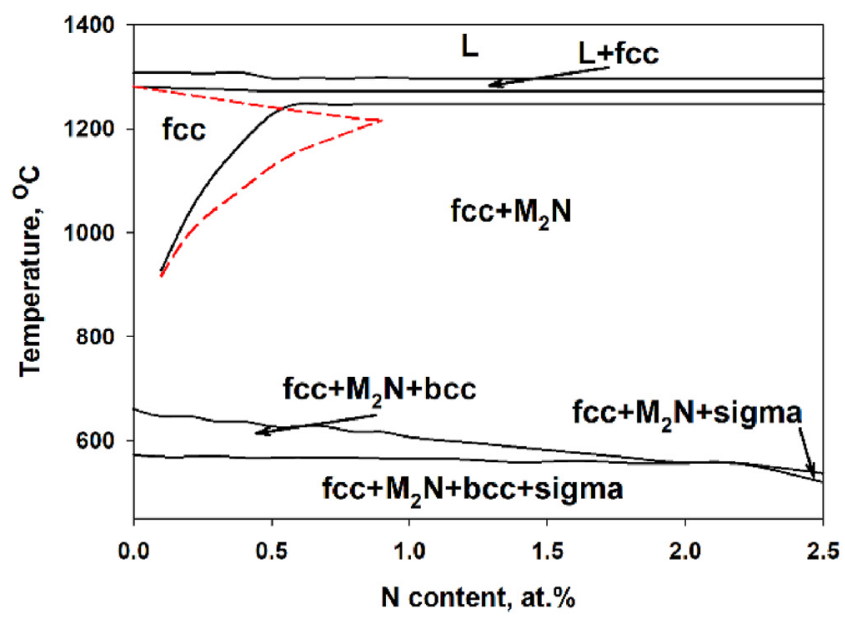

Fig. 8. Quasi-binary CoCrFeMnNi-N phase diagram constructed using Thermo-Calc software. The boundaries of a single fcc phase field in the $\mathrm{CoCrFeMnNi-C}$ binary system are also plotted with a dashed red line. (For interpretation of the references to colour in this figure legend, the reader is referred to the Web version of this article.)

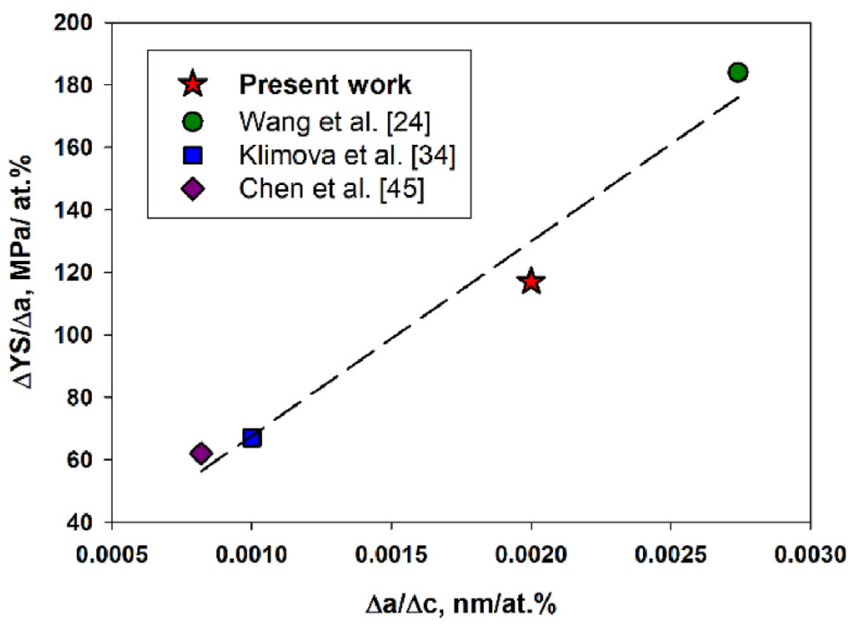

Fig. 9. Dependence between the solid solution strengthening coefficients $(\Delta Y S / \Delta c)$ at $293 \mathrm{~K}$ and lattice distortion $(\Delta a / \Delta c)$ in the investigated $\mathrm{CoCrFeMnNiN}_{\mathrm{x}}$ alloys and several other fcc HEAs doped with carbon.

designing the systems where the alloying elements strongly distort the lattice. However, note that unlike substitutional atoms [49,50], to the best authors' knowledge, there are currently no analytical models that can predict the lattice distortions in multicomponent HEAs due to interstitial alloying.

The solid solution strengthening also becomes $\approx 2.7$ times higher with a decrease in temperature: $117 \mathrm{MPa} / \mathrm{at} \% \mathrm{~N}$ at $293 \mathrm{~K}$ and $316 \mathrm{MPa} /$ at\% $\mathrm{N}$ at $77 \mathrm{~K}$ (Fig. 4). A similar increase in the solid solution strengthening was recently reported for the $\mathrm{CoCr}_{0.25} \mathrm{FeMnNi}-\mathrm{C}$ alloys [34], where the solid solution strengthening became $\approx 2.2$ times higher when the deformation temperature decreased from $293 \mathrm{~K}$ to $77 \mathrm{~K}$. The observed rise in strengthening can be attributed to a naturally higher lattice friction stress at lower temperatures [43].

The amount of nitrogen dissolved in the fcc matrix of the alloys can also control the operative plastic deformation mechanisms and therefore strain hardening capacity (Fig. 5), ductility, and ultimate strength of the alloys (Table 2). However, the experimental investigations revealed very limited changes in the deformed microstructures of the alloys with different $\mathrm{N}$ percentage. The observed structures were mostly associated with extensive planar dislocation slip both at $77 \mathrm{~K}$ and $293 \mathrm{~K}$ (Fig. 7). Planar dislocation slip was reported in the equiatomic CoCrFeMnNi alloy, especially during room temperature deformation [14,51,52]; besides extensive mechanical twinning was observed in cryogenic conditions, however $[14,15,17,51,53]$. The present results suggest that the addition of $\mathrm{N}$ suppressed deformation twinning at $77 \mathrm{~K}$.

Deformation mechanisms in fcc metals and alloys are strongly dependent on the stacking fault energy (SFE) value. Generally, mechanical twinning is expected in the alloys with low SFE [54]. The effect of $\mathrm{N}$ on the SFE value in nitrogen-containing austenitic steels was often found to be non-monotonic and depended strongly on the principal elements' concentrations [55-58]. The effect of $\mathrm{N}$ on SFE in the program alloys can be calculated as [59]:

$\gamma_{S F E}=2 \rho \Delta G_{f c c-h c p}+2 \sigma$

where $\gamma_{\text {SFE }}$ is the SFE value, $\Delta G_{\text {hcp-fcc }}$ is the difference in Gibbs free energy between the fcc and hcp phases, $\rho$ is the molar surface density along $\{111\}$ planes, and $\sigma$ is the interphase energy between the fcc and hcp phases [32,59]. The values of free energy for the $\gamma$ $\rightarrow \varepsilon$ phase transformation in the alloys were calculated using the Thermo-Calc software (Table 3).

The calculated $\Delta \mathrm{G}_{\text {hcp-fcc }}$ values suggest that $\mathrm{N}$ atoms in equiatomic fcc $\mathrm{CoCrFeMnNi} \mathrm{have} \mathrm{quite} \mathrm{a} \mathrm{weak} \mathrm{effect} \mathrm{on} \mathrm{SFE.} \mathrm{For} \mathrm{example,}$ the addition of 2 at.\% of $\mathrm{N}$ results in only $\sim 1 \%$ difference in the $\Delta \mathrm{G}_{\mathrm{hcp} \text {-fcc }}$ values. Therefore, the suppression of twinning in the $\mathrm{N}$ doped alloys can hardly be attributed to the SFE changes, at least in the examined range of nitrogen concentrations. However, nearly constant $\Delta \mathrm{G}_{\mathrm{hcp}}$-fcc values for the alloys with different $\mathrm{N}$ percentages are in accord with similar deformation mechanisms in the program alloys (Fig. 7) and also consistent for some experimental observation on nitrogen bearing austenitic steels [60].

The effect of nitrogen on deformation behavior of different austenitic steels was quite extensively studied [35,36,61-63]. Although these works often express conflicting views, it was supposed that the addition of certain amounts of $\mathrm{N}$ can suppress mechanical twinning in some steels due to short-range order (SRO) [61]. Note that the amount of $\mathrm{N}(0.4 \mathrm{wt} \%$ - $\approx 1.75$ at.\%) in the $316 \mathrm{~L}$ steel examined in Ref. [61] was fairly close to that for the program alloys in the current study. Strong affinity between $\mathrm{Cr}$ and $\mathrm{N}$ atoms result in atom couples formation which in turn leads to short-range ordering [35,64]. SRO benefits planar slip [65,66], however, it also suppresses twinning because local SRO needs to be destroyed on certain planes for twins growth. Yet at higher $\mathrm{N}$ concentrations dynamic strain aging makes slip more difficult and twinning can prevail again [61]. Note that existence of SRO in HEAs was suggested to affect mechanical properties strongly by the results of computational studies [67-71]; recently, some experimental confirmations have been obtained [72-74]. For example, in the interstitial boron doped fcc alloy the deformation-induced formation of SRO, associated with planar dislocation bands, has resulted in noticeable (by 32\%) increase in yield strength at $77 \mathrm{~K} \mathrm{[75].} \mathrm{In} \mathrm{the}$ investigated alloys the are no direct proofs for the SRO existence; the experimental confirmation of SRO requires additional studies. However, a comparison of the deformation substructure suggests

Table 3

Dependence of $\Delta \mathrm{G}_{\text {hcp-fcc }}$ at $293 \mathrm{~K}$ on the $\mathrm{N}$ concentration in equiatomic CoCrFeMnNi high entropy alloys.

\begin{tabular}{ll}
\hline $\mathrm{N}$ content, at.\% & $\Delta \mathrm{G}_{\mathrm{hcp}-\mathrm{fcc}}, \mathrm{kJ} / \mathrm{mole}$ \\
\hline 0 & 2.560 \\
0.5 & 2.555 \\
1.0 & 2.548 \\
2.0 & 2.530 \\
\hline
\end{tabular}


an inclination toward more "planar" dislocation substructures with an increase in the $\mathrm{N}$ content (compare Fig. $7 \mathrm{~b}$ and $\mathrm{d}$ for example). This might be an indirect indication of the SRO manifestation in the program alloys, which results in the observed suppression of twinning. The planar slip most probably resulted also in better strain hardening capacity of the alloys with a higher $\mathrm{N}$ content at room temperature (Fig. 5).

The alloys with low concentrations of $\mathrm{N}$ (0.5 and 1.0 at.\%) exhibited also better strain hardening (Fig. 5) and higher ductility (Table 2) with a decrease in temperature to $77 \mathrm{~K}$ that is typical of fcc high entropy alloys $[14,15]$. The increase in strain hardening of the alloys can be associated with higher dislocation density and/or more planar dislocation configurations (Fig. 7). On the contrary, however, strain hardening and ductility of the alloy with 2 at.\% of $\mathrm{N}$ significantly diminished with a decrease in the testing temperature; for example, ductility dropped from $67 \%$ to $8 \%$.

The decrease in ductility and fracture toughness in N-containing steels at cryogenic temperatures is a well-known phenomenon that is often attributed to the brittle to ductile transition [76-78]. Fractographic examinations confirmed the change in the fracture mode (from dimple to cleavage fracture) of the alloy with 2 at.\% of $\mathrm{N}$ with a decrease in temperature from $293 \mathrm{~K}$ to $77 \mathrm{~K}$ (Fig. 6). In steels, a cleavage-like fracture is often observed due to either mechanical twinning or development of planar slip [76,78]. Although further studies are required to establish the exact mechanisms responsible for fracture of the alloy with 2 at.\% $\mathrm{N}$; the presented results clearly suggest that in the CoCrFeMnNi alloy this amount of $\mathrm{N}$ has a threshold value which makes the alloys brittle at cryogenic conditions.

In summary, the presented results demonstrate that N-doped CoCrFeMnNi alloys can have a very attractive combination of strength and ductility at cryogenic temperature (Fig. 3, Table 2). The unique properties of the alloys can be mostly attributed to the strong solid solution effect and planar dislocation slip (Fig. 7). The alloys can therefore be considered as promising structural materials for cryogenic applications. Further improvement in properties can be archived after proper thermomechanical processing that can refine the fcc grains and result in the precipitation of fine nitride particles $[39,79,80]$.

\section{Conclusions}

In the present work, the structure and tensile mechanical properties of $\mathrm{CoCrFeMnNi} \mathrm{high} \mathrm{entropy} \mathrm{alloys} \mathrm{doped} \mathrm{with} \mathrm{different}$ amounts of $\mathrm{N}(0.5-2.0$ at.\%) in the as-cast condition were examined. The following conclusions were drawn:

1) The alloys with low $\mathrm{N}$ amounts (0.5-1.0 at.\%) had the single fcc phase coarse-grained microstructures. An increase in the $\mathrm{N}$ content to 2.0 at.\% resulted in the precipitation of a small amount $(<1 \%)$ of the $\mathrm{Cr}$-rich $\mathrm{M}_{2} \mathrm{~N}$ nitride particles at the fcc grain boundaries. Good solubility of $\mathrm{N}$ in the fcc solid solution of the $\mathrm{N}$-doped $\mathrm{CoCrFeMnNi}$ alloys was in reasonable agreement with the Thermo-Calc predictions. According to the quasi-binary equilibrium $\mathrm{CoCrFeMnNi-N}$ phase diagram, a narrow single fcc phase field after solidification existed even at a high $\mathrm{N}$ percentage.

2) The yield strength of the program alloys increased in proportion with the $\mathrm{N}$ percentage by $117 \mathrm{MPa} / \mathrm{at} \% \mathrm{~N}$ at $293 \mathrm{~K}$. With a decrease in the testing temperature the alloys became even stronger, and the strength increased by $316 \mathrm{MPa} / a t \% \mathrm{~N}$ at $77 \mathrm{~K}$. The increase in strength was attributed to the solid solution hardening. The comparison with the available information on other interstitial fcc HEAs suggested that the solid solution strengthening effect was proportional to the lattice distortion.
The ductility of the alloy with 0.5 and 1.0 at.\% of $\mathrm{N}$ increased with a decrease in the testing temperature while ductility of the alloy with 2 at.\% dropped from $67 \%$ at $293 \mathrm{~K}$ to $8 \%$ at $77 \mathrm{~K}$.

3 ) The plastic deformation of the N-doped alloys at both $77 \mathrm{~K}$ and $293 \mathrm{~K}$ was mostly associated with planar dislocation slip. Mechanical twinning was not revealed even at $77 \mathrm{~K}$.

\section{CRediT authorship contribution statement}

M. Klimova: Investigation, Writing - review \& editing, Visualization, Supervision. D. Shaysultanov: Investigation. A. Semenyuk: Investigation. S. Zherebtsov: Methodology, Writing - review \& editing. G. Salishchev: Conceptualization. N. Stepanov: Writing original draft, Visualization, Supervision, Funding acquisition.

\section{Declaration of competing interest}

The authors declare that they have no known competing financial interests or personal relationships that could have appeared to influence the work reported in this paper.

\section{Acknowledgments}

The authors gratefully acknowledge the financial support from the Russian Science Foundation Grant No. 18-19-00003. The authors are grateful to the personnel of the Joint Research Center, «Technology and Materials», Belgorod State University, for their assistance with the instrumental analysis.

\section{References}

[1] J.W. Yeh, S.-K Chen, S.J. Lin, J.Y. Gan, T.S. Chin, T.-T. Shun, C.H. Tsau, S.Y. Chang, Nanostructured high-entropy alloys with multiple principal elements: novel alloy design concepts and outcomes, Adv. Eng. Mater. 6 (2004) 299-303, https://doi.org/10.1002/adem.200300567.

[2] Y. Zhang, T.T. Zuo, Z. Tang, M.C. Gao, K.A. Dahmen, P.K. Liaw, Z.P. Lu, Microstructures and properties of high-entropy alloys, Prog. Mater. Sci. 61 (2014), https://doi.org/10.1016/j.pmatsci.2013.10.001.

[3] D.B.B. Miracle, O.N.N. Senkov, A critical review of high entropy alloys and related concepts, Acta Mater. 122 (2017) 448-511, https://doi.org/10.1016/ j.actamat.2016.08.081.

[4] E.P. George, D. Raabe, R.O. Ritchie, High-entropy alloys, Nat. Rev. Mater. (2019) 1, https://doi.org/10.1038/s41578-019-0121-4.

[5] S. Gorsse, D.B. Miracle, O.N. Senkov, Mapping the world of complex concentrated alloys, Acta Mater. 135 (2017) 177-187, https://doi.org/10.1016/ j.actamat.2017.06.027.

[6] E.J. Pickering, N.G. Jones, High-entropy alloys: a critical assessment of their founding principles and future prospects, Int. Mater. Rev. (2016) 183-202, https://doi.org/10.1080/09506608.2016.1180020.

[7] F. Otto, Y. Yang, H. Bei, E.P.P. George, Relative effects of enthalpy and entropy on the phase stability of equiatomic high-entropy alloys, Acta Mater. 61 (2013) 2628-2638, https://doi.org/10.1016/j.actamat.2013.01.042.

[8] M. Laurent-Brocq, L. Perrière, R. Pirès, Y. Champion, From high entropy alloys to diluted multi-component alloys: range of existence of a solid-solution, Mater. Des. 103 (2016) 84-89, https://doi.org/10.1016/j.matdes.2016.04.046.

[9] B. Cantor, I.T.H. Chang, P. Knight, A.J.B. Vincent, Microstructural development in equiatomic multicomponent alloys, Mater. Sci. Eng. A. 375 (2004) 213-218, https://doi.org/10.1016/j.msea.2003.10.257.

[10] F. Otto, A. Dlouhý, K.G. Pradeep, M. Kuběnová, D. Raabe, G. Eggeler, E.P. George, Decomposition of the single-phase high-entropy alloy CrMnFeCoNi after prolonged anneals at intermediate temperatures, Acta Mater. 112 (2016), https://doi.org/10.1016/j.actamat.2016.04.005.

[11] E.J. Pickering, R. Muñoz-Moreno, H.J. Stone, N.G. Jones, Precipitation in the equiatomic high-entropy alloy CrMnFeCoNi, Scripta Mater. 113 (2016), https://doi.org/10.1016/j.scriptamat.2015.10.025.

[12] M.V. Klimova, D.G. Shaysultanov, S.V. Zherebtsov, N.D. Stepanov, Effect of second phase particles on mechanical properties and grain growth in a CoCrFeMnNi high entropy alloy, Mater. Sci. Eng. A. 748 (2019) 228-235, https://doi.org/10.1016/J.MSEA.2019.01.112.

[13] B. Schuh, F. Mendez-Martin, B. Völker, E.P. George, H. Clemens, R. Pippan, A. Hohenwarter, Mechanical properties, microstructure and thermal stability of a nanocrystalline CoCrFeMnNi high-entropy alloy after severe plastic deformation, Acta Mater. 96 (2015) 258-268, https://doi.org/10.1016/ j.actamat.2015.06.025. 
[14] F. Otto, A. Dlouhý, C. Somsen, H. Bei, G. Eggeler, E.P. George, The influences of temperature and microstructure on the tensile properties of a $\mathrm{CoCrFeMnNi}$ high-entropy alloy, Acta Mater. 61 (2013) 5743-5755, https://doi.org/ 10.1016/j.actamat.2013.06.018.

[15] B. Gludovatz, A. Hohenwarter, D. Catoor, E.H. Chang, E.P. George, R.O. Ritchie, A fracture-resistant high-entropy alloy for cryogenic applications, Science 345 (2014) 1153-1158, https://doi.org/10.1126/science.1254581, 80-.

[16] B. Gludovatz, A. Hohenwarter, K.V.S. Thurston, H. Bei, Z. Wu, E.P. George, R.O. Ritchie, Exceptional damage-tolerance of a medium-entropy alloy $\mathrm{CrCoNi}$ at cryogenic temperatures, Nat. Commun. (2016), https://doi.org/10.1038/ ncomms10602.

[17] Z. Zhang, M.M. Mao, J. Wang, B. Gludovatz, Z. Zhang, S.X. Mao, E.P. George, Q. Yu, R.O. Ritchie, Nanoscale origins of the damage tolerance of the highentropy alloy CrMnFeCoNi, Nat. Commun. 6 (2015) 10143, https://doi.org/ 10.1038/ncomms10143.

[18] O.N. Senkov, G.B. Wilks, D.B. Miracle, C.P. Chuang, P.K. Liaw, Refractory highentropy alloys, Intermetallics 18 (2010) 1758-1765, https://doi.org/10.1016/ j.intermet.2010.05.014.

[19] O.N. Senkov, G.B. Wilks, J.M. Scott, D.B. Miracle, Mechanical properties of Nb 25Mo 25Ta 25W 25 and V 20Nb 20Mo 20Ta 20W 20 refractory high entropy alloys, Intermetallics 19 (2011) 698-706, https://doi.org/10.1016/ j.intermet.2011.01.004.

[20] O.N. Senkov, S. Gorsse, D.B. Miracle, High temperature strength of refractory complex concentrated alloys, Acta Mater. 175 (2019) 394-405, https:// doi.org/10.1016/j.actamat.2019.06.032.

[21] Z. Wang, I. Baker, Interstitial strengthening of a f.c.c. FeNiMnAlCr high entropy alloy, Mater. Lett. 180 (2016) 153-156, https://doi.org/10.1016/ j.matlet.2016.05.122.

[22] N.D. Stepanov, N.Y. Yurchenko, M.A. Tikhonovsky, G.A. Salishchev, Effect of carbon content and annealing on structure and hardness of the CoCrFeNiMnbased high entropy alloys, J. Alloys Compd. 687 (2016) 59-71, https://doi.org/ 10.1016/j.jallcom.2016.06.103.

[23] Z. Li, C.C. Tasan, H. Springer, B. Gault, D. Raabe, Interstitial atoms enable joint twinning and transformation induced plasticity in strong and ductile highentropy alloys, Sci. Rep. 7 (2017) 40704, https://doi.org/10.1038/srep40704.

[24] Z. Wang, I. Baker, Z. Cai, S. Chen, J.D. Poplawsky, W. Guo, The effect of interstitial carbon on the mechanical properties and dislocation substructure evolution in Fe40.4Ni11.3Mn34.8Al7.5Cr6 high entropy alloys, Acta Mater. 120 (2016), https://doi.org/10.1016/j.actamat.2016.08.072.

[25] Z. Wang, I. Baker, W. Guo, J.D. Poplawsky, The effect of carbon on the microstructures, mechanical properties, and deformation mechanisms of thermo-mechanically treated Fe40.4Ni11.3Mn34.8Al7.5Cr6 high entropy alloys, Acta Mater. 126 (2017) 346-360, https://doi.org/10.1016/ j.actamat.2016.12.074.

[26] Z. Li, Interstitial equiatomic CoCrFeMnNi high-entropy alloys: carbon content, microstructure, and compositional homogeneity effects on deformation behavior, Acta Mater. 164 (2019) 400-412, https://doi.org/10.1016/ j.actamat.2018.10.050.

[27] Z. Wu, C.M. Parish, H. Bei, Nano-twin mediated plasticity in carbon-containing FeNiCoCrMn high entropy alloys, J. Alloys Compd. 647 (2015) 815-822, https://doi.org/10.1016/j.jallcom.2015.05.224.

[28] M.V. Klimova, D.G. Shaysultanov, R.S. Chernichenko, V.N. Sanin, N.D. Stepanov, S.V. Zherebtsov, A.N. Belyakov, Recrystallized microstructures and mechanical properties of a C-containing CoCrFeNiMn-type high-entropy alloy, Mater. Sci. Eng. A. 740-741 (2019) 201-210, https://doi.org/10.1016/ j.msea.2018.09.113.

[29] J. Chen, Z. Yao, X. Wang, Y. Lu, X. Wang, Y. Liu, X. Fan, Effect of C content on microstructure and tensile properties of as-cast CoCrFeMnNi high entropy alloy, Mater. Chem. Phys. 210 (2018) 136-145, https://doi.org/10.1016/ j.matchemphys.2017.08.011.

[30] J. Peng, Z. Li, L. Fu, X. Ji, Z. Pang, A. Shan, Carbide precipitation strengthening in fine-grained carbon-doped FeCoCrNiMn high entropy alloy, J. Alloys Compd. (2019), https://doi.org/10.1016/J.JALLCOM.2019.06.204.

[31] N.D. Stepanov, D.G. Shaysultanov, R.S. Chernichenko, N.Y. Yurchenko, S. V Zherebtsov, M.A. Tikhonovsky, G.A. Salishchev, Effect of thermomechanical processing on microstructure and mechanical properties of the carboncontaining CoCrFeNiMn high entropy alloy, J. Alloys Compd. 693 (2017) 394-405, https://doi.org/10.1016/j.jallcom.2016.09.208.

[32] M. Klimova, N. Stepanov, D. Shaysultanov, R. Chernichenko, N. Yurchenko, V. Sanin, S. Zherebtsov, Microstructure and mechanical properties evolution of the $\mathrm{Al}$, C-containing CoCrFeNiMn-type high-entropy alloy during cold rolling, Materials (Basel) 11 (2017) 53, https://doi.org/10.3390/ma11010053.

[33] Z. Wang, W. Lu, D. Raabe, Z. Li, On the mechanism of extraordinary strain hardening in an interstitial high-entropy alloy under cryogenic conditions, J. Alloys Compd. 781 (2019) 734-743, https://doi.org/10.1016/ J.JALLCOM.2018.12.061.

[34] M.V. Klimova, A.O. Semenyuk, D.G. Shaysultanov, G.A. Salishchev, S.V. Zherebtsov, N.D. Stepanov, Effect of carbon on cryogenic tensile behavior of CoCrFeMnNi-type high entropy alloys, J. Alloys Compd. 811 (2019) 152000, https://doi.org/10.1016/j.jallcom.2019.152000.

[35] V.G. (Valentin G. Gavriliuk, H. Berns, High Nitrogen Steels : Structure, Properties, Manufacture, Applications, Springer Berlin Heidelberg, 1999.

[36] M.L.G. Byrnes, M. Grujicic, W.S. Owen, Nitrogen strengthening of a stable austenitic stainless steel, Acta Metall. 35 (1987) 1853-1862, https://doi.org/ 10.1016/0001-6160(87)90131-3.
[37] T. Sakamoto, Y. Nakagawa, I. Yamauchi, T. Zaizen, H. Nakajima, S. Shimamoto, Nitrogen-containing $25 \mathrm{Cr}-13 \mathrm{Ni}$ stainless steel as a cryogenic structural material, in: Adv. Cryog. Eng, Plenum Press, 1984, pp. 137-144.

[38] I. Moravcik, J. Cizek, L. Gouvea, J. Cupera, I. Guban, I. Dlouhy, Nitrogen interstitial alloying of CoCrFeMnNi high entropy alloy through reactive powder milling, Entropy 21 (2019) 363, https://doi.org/10.3390/e21040363.

[39] D. Edgard Jodi, J. Park, N. Park, Strengthening of ultrafine-grained equiatomic CoCrFeMnNi high-entropy alloy by nitrogen addition, Mater. Lett. (2019) 126772, https://doi.org/10.1016/j.matlet.2019.126772.

[40] D.E. Jodi, J. Park, B. Straumal, N. Park, Investigation on the precipitate formation and behavior in nitrogen-containing equiatomic CoCrFeMnNi highentropy alloy, Mater. Lett. 258 (2020) 126806, https://doi.org/10.1016/ j.matlet.2019.126806.

[41] F. Xiong, R. Fu, Y. Li, D. Sang, Effects of nitrogen alloying and friction stir processing on the microstructures and mechanical properties of CoCrFeMnNi high-entropy alloys, J. Alloys Compd. 822 (n.d.) 153512. doi:10.1016/ j.jallcom.2019.153512.

[42] B. Gludovatz, E.P. George, R.O. Ritchie, Processing, Microstructure and mechanical properties of the CrMnFeCoNi high-entropy alloy, JOM (J. Occup. Med.) (2015), https://doi.org/10.1007/s11837-015-1589-z.

[43] Z. Wu, H. Bei, G.M. Pharr, E.P. George, Temperature dependence of the mechanical properties of equiatomic solid solution alloys with face-centered cubic crystal structures, Acta Mater. 81 (2014), https://doi.org/10.1016/ j.actamat.2014.08.026

[44] D.B. Miracle, J.D. Miller, O.N. Senkov, C. Woodward, M.D. Uchic, J. Tiley, Exploration and development of high entropy alloys for structural applications, Entropy 16 (2014) 494-525, https://doi.org/10.3390/e16010494.

[45] L.B. Chen, R. Wei, K. Tang, J. Zhang, F. Jiang, L. He, J. Sun, Heavy carbon alloyed FCC-structured high entropy alloy with excellent combination of strength and ductility, Mater. Sci. Eng. A. 716 (2018) 150-156, https://doi.org/10.1016 j.msea.2018.01.045.

[46] J. Li, B. Gao, Y. Wang, X. Chen, Y. Xin, S. Tang, B. Liu, Y. Liu, M. Song, Microstructures and mechanical properties of nano carbides reinforced $\mathrm{CoCr}$ FeMnNi high entropy alloys, J. Alloys Compd. 792 (2019) 170-179, https:// doi.org/10.1016/J.JALLCOM.2019.03.403.

[47] R.L. Fleischer, Substitutional solution hardening, Acta Metall. 11 (1963) 203-209, https://doi.org/10.1016/0001-6160(63)90213-X.

[48] R. Labusch, A statistical theory of solid solution hardening, Phys. Status Solidi 41 (1970) 659-669, https://doi.org/10.1002/pssb.19700410221.

[49] I. Toda-Caraballo, P.E.J. Rivera-Díaz-del-Castillo, Modelling solid solution hardening in high entropy alloys, Acta Mater. 85 (2015) 14-23, https:// doi.org/10.1016/j.actamat.2014.11.014.

[50] C. Varvenne, A. Luque, W.A. Curtin, Theory of strengthening in fcc high entropy alloys, Acta Mater. 118 (2016), https://doi.org/10.1016 j.actamat.2016.07.040.

[51] G. Laplanche, A. Kostka, O.M.M. Horst, G. Eggeler, E.P.P. George, Microstructure evolution and critical stress for twinning in the CrMnFeCoNi highentropy alloy, Acta Mater. 118 (2016) 152-163, https://doi.org/10.1016/ j.actamat.2016.07.038

[52] C. Haase, L.A. Barrales-Mora, Influence of deformation and annealing twinning on the microstructure and texture evolution of face-centered cubic highentropy alloys, Acta Mater. 150 (2018) 88-103, https://doi.org/10.1016 j.actamat.2018.02.048.

[53] I.V. Kireeva, Y.I. Chumlyakov, Z.V. Pobedennaya, A.V. Vyrodova, I. Karaman, Twinning in [001]-oriented single crystals of CoCrFeMnNi high-entropy alloy at tensile deformation, Mater. Sci. Eng. A. 713 (2018) 253-259, https:// doi.org/10.1016/j.msea.2017.12.059.

[54] A. Saeed-Akbari, J. Imlau, U. Prahl, W. Bleck, Derivation and variation in composition-dependent stacking fault energy maps based on subregular solution model in high-manganese steels, Metall. Mater. Trans. A Phys. Metall. Mater. Sci. 40 (2009) 3076-3090, https://doi.org/10.1007/s11661-009-00508 .

[55] L. Mosecker, A. Saeed-Akbari, Nitrogen in chromium-manganese stainless steels: a review on the evaluation of stacking fault energy by computational thermodynamics, Sci. Technol. Adv. Mater. 14 (2013), 033001, https://doi.org/ 10.1088/1468-6996/14/3/033001.

[56] V. Gavriljuk, Y. Petrov, B. Shanina, Effect of nitrogen on the electron structure and stacking fault energy in austenitic steels, Scripta Mater. 55 (2006) 537-540, https://doi.org/10.1016/j.scriptamat.2006.05.025.

[57] I.A. Yakubtsov, A. Ariapour, D.D. Perovic, Effect of nitrogen on stacking fault energy of f.c.c. iron-based alloys, Acta Mater. 47 (1999) 1271-1279, https:// doi.org/10.1016/S1359-6454(98)00419-4.

[58] M. Ojima, Y. Tomota, Y. Katada, Y. Adachi, Y. Kaneko, K. Kuroda, H. Saka, Weak beam TEM study on stacking fault energy of high nitrogen steels, Steel Res. Int. 80 (2009) 477-481, https://doi.org/10.2374/SRI09SP038.

[59] S.M. Cotes, A.F. Guillermet, M. Sade, Fcc/Hcp martensitic transformation in the Fe-Mn system: Part II. Driving force and thermodynamics of the nucleation process, Metall. Mater. Trans. 35 (2004) 83-91, https://doi.org/10.1007/ s11661-004-0111-y.

[60] R.P. Reed, Nitrogen in austenitic stainless steels, JOM (J. Occup. Med.) 41 (1989) 16-21, https://doi.org/10.1007/BF03220991.

[61] I. Karaman, H. Sehitoglu, H.J. Maier, Y.I. Chumlyakov, Competing mechanisms and modeling of deformation in austenitic stainless steel single crystals with and without nitrogen, Acta Mater. 49 (2001) 3919-3933, https://doi.org/ 10.1016/S1359-6454(01)00296-8. 
[62] T.H. Lee, C.S. Oh, S.J. Kim, S. Takaki, Deformation twinning in high-nitrogen austenitic stainless steel, Acta Mater. 55 (2007) 3649-3662, https://doi.org/ 10.1016/j.actamat.2007.02.023.

[63] S. Kubota, Y. Xia, Y. Tomota, Work-hardening behavior and evolution of dislocation-microstructures in high-nitrogen bearing austenitic steels, ISIJ Int. 38 (1998) 474-481, https://doi.org/10.2355/isijinternational.38.474.

[64] M. Grujicic, W.S. Owen, Models of short-range order in a face-centered cubic $\mathrm{Fe}-\mathrm{Ni}$-Cr alloy with a high concentration of nitrogen, Acta Metall. Mater. 43 (1995) 4201-4211, https://doi.org/10.1016/0956-7151(95)00107-7.

[65] S.I.I. Hong, C. Laird, Mechanisms of slip mode modification in F.C.C. solid solutions, Acta Metall. Mater. 38 (1990) 1581-1594, https://doi.org/10.1016/ 0956-7151(90)90126-2.

[66] V. Gerold, H.P.P. Karnthaler, On the origin of planar slip in f.c.c. alloys, Acta Metall. 37 (1989) 2177-2183, https://doi.org/10.1016/0001-6160(89)901430 .

[67] O.J. Li, H. Sheng, E. Ma, Strengthening in multi-principal element alloys with local-chemical-order roughened dislocation pathways, Nat. Commun. 10 (2019) 1-11, https://doi.org/10.1038/s41467-019-11464-7.

[68] J. Ding, Q. Yu, M. Asta, R.O. Ritchie, Tunable stacking fault energies by tailoring local chemical order in CrCoNi medium-entropy alloys, Proc. Natl. Acad. Sci. U.S.A. 115 (2018) 8919-8924, https://doi.org/10.1073/pnas.1808660115.

[69] A. Fernández-Caballero, J.S. Wróbel, P.M. Mummery, D. Nguyen-Manh, Shortrange order in high entropy alloys: theoretical formulation and application to Mo-Nb-Ta-V-W system, J. Phase Equilibria Diffus. 38 (2017) 391-403, https:// doi.org/10.1007/s11669-017-0582-3.

[70] E. Antillon, C. Woodward, S.I. Rao, B. Akdim, T.A. Parthasarathy, Chemical short range order strengthening in a model FCC high entropy alloy, Acta Mater. 190 (2020) 29-42, https://doi.org/10.1016/j.actamat.2020.02.041.

[71] X.G. Li, C. Chen, H. Zheng, Y. Zuo, S.P. Ong, Complex strengthening mechanisms in the NbMoTaW multi-principal element alloy, Npj Comput. Mater. 6 (2020) 1-10, https://doi.org/10.1038/s41524-020-0339-0.

[72] Y. Ma, Q. Wang, C. Li, L.J. Santodonato, M. Feygenson, C. Dong, P.K. Liaw,
Chemical short-range orders and the induced structural transition in highentropy alloys, Scripta Mater. 144 (2018) 64-68, https://doi.org/10.1016/ J.SCRIPTAMAT.2017.09.049.

[73] R. Zhang, S. Zhao, J. Ding, Y. Chong, T. Jia, C. Ophus, M. Asta, R.O. Ritchie, A.M. Minor, Short-range order and its impact on the CrCoNi medium-entropy alloy, Nature 581 (2020) 283-287, https://doi.org/10.1038/s41586-020-2275-

[74] Q. Ding, Y. Zhang, X. Chen, X. Fu, D. Chen, S. Chen, L. Gu, F. Wei, H. Bei, Y. Gao, M. Wen, J. Li, Z. Zhang, T. Zhu, R.O. Ritchie, Q. Yu, Tuning element distribution, structure and properties by composition in high-entropy alloys, Nature 574 (2019) 223-227, https://doi.org/10.1038/s41586-019-1617-1.

[75] Z. Li, H.H. Lee, S.H. Shim, J.H. Jang, Short-range order strengthening in borondoped high-entropy alloys for cryogenic applications, Acta Mater. (2020), https://doi.org/10.1016/j.actamat.2020.04.052.

[76] J.B. Vogt, A. Messai, J. Foct, Cleavage fracture of austenite induced by nitrogen supersaturation, Scripta Metall. Mater. 31 (1994) 549-554, https://doi.org/ 10.1016/0956-716X(94)90142-2.

[77] P. Müllner, C. Solenthaler, P.J. Uggowitzer, M.O. Speidel, Brittle fracture in austenitic steel, Acta Metall. Mater. 42 (1994) 2211-2217, https://doi.org/ 10.1016/0956-7151(94)90300-X.

[78] Y. Tomota, Y. Xia, K. Inoue, Mechanism of low temperature brittle fracture in high nitrogen bearing austenitic steels, Acta Mater. 46 (1998) 1577-1587, https://doi.org/10.1016/S1359-6454(97)00350-9.

[79] N.D. Stepanov, D.G. Shaysultanov, R.S. Chernichenko, D.M. Ikornikov, V.N. Sanin, S.V. Zherebtsov, Mechanical properties of a new high entropy alloy with a duplex ultra-fine grained structure, Mater. Sci. Eng. A. 728 (2018) 54-62, https://doi.org/10.1016/j.msea.2018.04.118.

[80] B. Gwalani, V. Soni, M. Lee, S. Mantri, Y. Ren, R. Banerjee, Optimizing the coupled effects of Hall-Petch and precipitation strengthening in a Al0.3CoCrFeNi high entropy alloy, Mater. Des. 121 (2017) 254-260, https:// doi.org/10.1016/j.matdes.2017.02.072. 